\title{
TRES MODELOS DE OPOSICIÓN POR CONVERSIÓN EN UN DICCIONARIO HISTÓRICO
}

\author{
RAFAEL GARCÍA PÉREZ \\ Universidad Carlos III de Madrid \\ Instituto de Investigación Rafael Lapesa (Real Academia Española)
}

\section{INTRODUCCIÓN}

El presente trabajo se inserta en un proyecto que pretende examinar una serie de problemas técnicos planteados por la elaboración de un diccionario histórico. Como hemos ido poniendo de manifiesto en otros lugares ${ }^{1}$, los avances en los ámbitos de la Informática y de la Lingüística nos permiten concebir el diseño de la obra desde una perspectiva relacional, con la idea de explicar la evolución del léxico en su conjunto, evitando así las restricciones que impone el estudio de las unidades aisladas. Ya en algunos artículos anteriores se mostraron las conexiones entre las palabras desde un punto de vista genético ${ }^{2}$, desde el punto de vista de algunas combinaciones específicas —en concreto los verbos de apoyo y los sustantivos predicativos ${ }^{3}$ - y desde el punto de vista de la sinonimia ${ }^{4}$. Ahora pretendo dar un paso más en la comprensión de ese entramado complejo de relaciones capaces de intervenir en la evolución del significado léxico.

Dentro de esa red de relaciones, el concepto de oposición tiene enorme re-

\footnotetext{
${ }_{1}^{1}$ José Antonio Pascual Rodríguez y Rafael García Pérez, «Un nuevo Diccionario histórico de la lengua española» (en prensa).

2 José Antonio Pascual Rodríguez y Rafael García Pérez, «Las relaciones entre las palabras en un diccionario histórico: la relación genética», Historia del léxico español. Anejos de la Revista de Lexicografía, 5, Mar Campos Souto, Rosalía Cotelo García, José Ignacio Pérez Pascual, eds., A Coruña, Universidade da Coruña, 2007, págs. 109-124.

${ }^{3}$ Rafael García Pérez, «¿Desde cuándo se cometen delitos? Relaciones entre léxico y sintaxis en la evolución histórica de la lengua del Derecho penal», Palabras, norma, discurso. En memoria de Fernando Lázaro Carreter, Luis Santos Río, Julio Borrego Nieto, Juan Felipe García Santos, José J. Gómez Asencio, Emilio Prieto de los Mozos, eds., Salamanca, Universidad de Salamanca, 2005, págs. 509-519.

${ }^{4}$ Rafael García Pérez, «La ordenación de las acepciones en un diccionario histórico», Revista de lexicografía, X, 2004, págs. 103-131.
} 
levancia. Desde hace bastante tiempo, la Semántica ha considerado que forma parte del comportamiento humano la tendencia a «polarizar la experiencia y el juicio» ${ }^{5}$ y no ha dejado de insistirse en la fascinación que han ejercido y siguen ejerciendo las relaciones de oposición en la mente de los hablantes ${ }^{6}$. En la actualidad, este concepto parece despertar interés incluso fuera del propio marco de los estudios ligados al léxico, como sucede en las investigaciones relativas a la adquisición de un idioma durante la infancia, las asociaciones de palabras, etc. ${ }^{7}$.

Estas relaciones, básicas en la estructuración semántica de una lengua, han tenido, además, enorme importancia en la historia del vocabulario. Han favorecido procesos de cambio paralelos entre las palabras que las constituían, como sucedió, por ejemplo, con los adjetivos alto y bajo que, manteniendo sus relaciones de oposición, experimentaron conjuntamente una extensión de significado; así, se empezaron a aplicar a las corrientes de agua en general con el sentido de 'cercanía o lejanía del origen', y hoy en día no resulta extraño oír sintagmas como Alto Ebro y Bajo Ebro para referirse, respectivamente, a las partes de este río más próximas y más alejadas de su nacimiento. Del mismo modo, si nos fiamos de la cronología, alto y bajo pudieron empezar a aplicarse en el s. XIV a los instrumentos y a los sonidos en general para indicar su grado de sonoridad $^{8}$.

Pero las palabras dotadas de acepciones opuestas no siempre han permanecido estables ni han evolucionado en la misma dirección, pues han llegado a sufrir desequilibrios de los que es necesario dar cuenta:

- Algunos de ellos son consecuencia de una evolución independiente de uno de los miembros de la relación, como sucede, por ejemplo, con el adjetivo ausente. Desde el principio (segunda mitad del s. XIII) estableció una oposición con el adjetivo presente para indicar si un ente animado o inanimado se hallaba en un lugar o apartado de él, pero desarrolló al mismo tiempo, al menos desde finales del s. XIII, un nuevo significado ('exento, libre'), para el que no se estableció una relación de oposición paralela.

\footnotetext{
5 John Lyons, Introduction to Theoretical Linguistics, London, Cambridge University Press, 1968, pág. 469.

${ }^{6}$ Alan Cruse, Lexical Semantics, Cambridge, Cambridge University Press, 1986, pág. 197.

7 Steve Jones, Antonymy. A corpus-based perspective, London - New York, Routledge, 2002, págs. 2-7.

${ }^{8}$ Es curioso que en el $\mathrm{DH}$, para este caso, se cite expresamente en la entrada alto (acepción 14.b.) que «se opone a bajo o dulce». Se trata, sencillamente, de un intento de delimitar mejor la paráfrasis definitoria, pues el $D H$, generalmente, no suele darnos pistas sobre las relaciones entre las palabras, ni mucho menos sobre su evolución semántica paralela o divergente.
} 
- Otros desequilibrios se deben a transformaciones léxicas externas que han podido alterar, a su vez, otras conexiones previas, principalmente genéticas o sinonímicas. No es raro, por tanto, que un cambio en cualquiera de las unidades provoque alteraciones en otras cercanas a ella y termine dando lugar a una reestructuración del conjunto.

- En el caso de vestir que, en su acepción 'cubrir o adornar el cuerpo con ropa', se oponía a desnudar desde los inicios del castellano, nos encontramos con que, al menos desde el s. XV, siguiendo un proceso de regularización morfológica, apareció la forma desvestir, dotada del mismo significado, que, naturalmente, entró en competencia con el antiguo opuesto sin llegar a desplazarlo por completo. Así, en la actualidad, podemos decir que existen dos antónimos canónicos del mismo vocablo, si bien utilizados en contextos distintos y con diferentes connotaciones. Ahora bien, en casos similares, la historia puede ofrecernos resultados diferentes; en acortar, que se oponía en igual medida a alargar que a alongar (ambos con el sentido de 'dar mayor longitud a una cosa'), la desaparición del segundo de los antónimos (s. XIX) ha hecho que la antonimia canónica solo afecte en la actualidad al par alargar-acortar.

- Especialmente interesantes resultan ciertos procesos históricos de reestructuración morfológica. Es el caso del verbo hacer en su acepción general de 'producir una nueva realidad material'. Desde los primeros tiempos del castellano, esta acepción tuvo su reverso en los verbos deshacer y destruir. La pugna entre las dos formas verbales se resolvió, contra todo lo previsible, en favor de la segunda, que terminó imponiéndose como antónimo absoluto para toda realidad material. El problema es que la introducción más tardía de la forma culta construir, derivada del antiguo término latino STRUERE, como el propio destruir, acabó arrastrando este último, de modo que en la actualidad, especialmente cuando el primero es capaz de seleccionar también con naturalidad cualquier tipo de objeto físico ${ }^{9}$, ha hecho que ambos verbos se presenten en la mente de los hablantes como reversos y que la antigua oposición hacer-destruir, se considere menos «canónica» que la del par construir-destruir.

- En el caso de los verbos de apoyo, las relaciones de oposición son especialmente complejas. Así, en la Edad Media era frecuente la combinación de los verbos hacer y sufrir con la clase que podríamos denominar <violencia>, formada por sustantivos como fuerza, violencia,

\footnotetext{
9 Rafael García Pérez, ¿Qué hacíamos y qué hacemos? El verbo hacer en la historia del español, San Millán de la Cogolla, Cilengua, 2007.
} 
etc. A partir del s. XV, se introduce en castellano, directamente del latín, la variante ejercer, que con el tiempo terminará desplazando a hacer y se convertirá en el verbo de apoyo apropiado a la clase, sin que ello implique transformación alguna respecto al converso sufrir. De hecho, en la actualidad conservamos aún el par anómalo ejercer (e incluso usar o utilizar)-sufrir.

- Las relaciones de oposición pueden haberse vuelto difusas, como ya se señaló en otro lugar ${ }^{10}$. La incorporación del italianismo abandonar al castellano supuso una ruptura de la antigua oposición amparar-desamparar, pues el nuevo vocablo terminó imponiéndose en el uso como antónimo del primero y desplazando definitivamente a su competidor más antiguo. Ahora bien, la desaparición de este llevó aparejada la decadencia de amparar, al que sustituyeron una serie de sinónimos (recoger, recuperar, etc.), con los que se trató de rellenar, con mejor o peor fortuna, el hueco dejado por aquel.

- También puede suceder - y es necesario tenerlo presente- que dos formas léxicas aparentemente opuestas (opuestas por su forma) no sean antónimas en ningún caso. Los verbos abonar y amalar, derivados de los adjetivos bueno y malo no han desarrollado, tras el proceso de transformación, acepciones que puedan considerarse propiamente contrarias. En realidad, amalar se utilizó mucho menos frecuentemente que abonar y desde el primer momento (s. XVI) tomó como base la acepción 'enfermo' del adjetivo malo, para la que no existía un correlato en abonar. La acepción 'hacer mala una cosa', recogida en el $D H$ es muy problemática, pues el único ejemplo con que contamos es un texto citado en la edición del 1770 del Diccionario de Autoridades, y no está respaldada por ninguna ocurrencia en el corpus ${ }^{11}$. Este único caso no parece suficiente para establecer con certeza la extensión de esta acepción ni su relación con los significados de abonar ${ }^{12}$.

El hecho es que resulta imprescindible tener en cuenta las relaciones de oposición para entender la evolución semántica de las palabras, así como las regularidades o irregularidades existentes en el léxico actual.

\footnotetext{
10 José Antonio Pascual y Rafael García Pérez, 2007, op. cit.

${ }^{11}$ REAL ACADEMIA ESPAÑOLA: Banco de datos (CORDE) [en línea]. Corpus diacrónico del español. <http://www.rae.es> [12-02-2007].

${ }^{12}$ Debería formar parte, por el momento, de ese apartado que en otro lugar hemos llamado «formas de interés filológico». Cfr. José Antonio Pascual y Rafael García Pérez, «La organización de los materiales en un diccionario histórico: las formas de interés filológico», Palabra sobre palabra. Estudios ofrecidos a Paz Battaner, Elisenda Bernal, Janet de Cesaris, eds., Barcelona, Institut Universitari de Lingüística Aplicada, Universitat Pompeu Fabra, 2006, págs. 189-200.
} 
Las relaciones de oposición forman una parte importante de los hechos de los que se ocupa la Semántica ${ }^{13}$, que ha puesto de manifiesto la complejidad de este concepto estableciendo clases bien delimitadas por su significado y comportamiento. Es necesario partir de estas clases si queremos trabajar con coherencia desde un punto de vista histórico. Ahora bien, en un diccionario concebido dentro de un marco relacional, no basta con aplicar las distinciones semánticas a los pares de opuestos de modo aislado, sino que hay que tomar en consideración el resto de las palabras más directamente vinculadas a ellos y especificar sus implicaciones. Basándome en el CORDE, me centraré en estas páginas en el estudio de las relaciones de oposición por conversión aplicadas a los verbos transitivos triactanciales ${ }^{14}$.

\section{TRES MODELOS DE RELACIONES DE OPOSICIÓN POR CONVERSIÓN}

Las relaciones de oposición por conversión son aquellas en las que existe un cambio de perspectiva, de modo que las palabras implicadas, tras un proceso de permutación de sus argumentos, expresan la misma idea, pero desde el punto de vista contrario. Así, el par encima-debajo constituiría un ejemplo clásico de oposición por conversión, ya que, para expresar la misma idea, a la estructura (1) a continuación le correspondería la estructura (2):

(1) El cuaderno está encima del libro.

(2) El libro está debajo del cuaderno.

Este tipo de relaciones de oposición son especialmente interesantes en el caso de los verbos y, especialmente, en el de los verbos transitivos. Por su importancia en la confección de un diccionario histórico, podrían distinguirse, al menos, tres modelos; cabría ejemplificarlos por medio de las siguientes palabras:
a) el par comprar-vender
b) el verbo alquilar
c) el verbo legar

\subsection{El caso del par «comprar-vender»}

Comprar y vender son dos conversos canónicos que aparecen desde los primeros testimonios del español. Como en la actualidad, el primero significaba

13 Vid., por ejemplo, Alan Cruse, Meaning in language: An introduction to Semantics and Pragmatics, Oxford, Oxford University Press, 2004.

14 Probablemente los verbos intransitivos responderían a otros modelos. He escogido los verbos transitivos triactanciales por su especial complejidad. 
'adquirir una cosa por un precio', y el segundo, en consecuencia, 'ceder una cosa por un precio'. Sintácticamente, se configuraban como verbos triactanciales, pues exigían - y siguen exigiendo- la presencia de un sujeto, un objeto directo $\mathrm{y}$, al menos, un objeto indirecto como argumentos obligatorios:

...si no quisieren comprarla, el Rey non gela venderá (1202).

2.1.1. La temprana separación de los dos sentidos conversos en dos formas léxicas distintas hizo que los derivados mantuvieran el mismo sistema de oposición. Así, los sustantivos en -dor, por ejemplo, que se interpretan como predicados agentivos, capaces de regir, al menos en ciertos contextos, el complemento directo de la forma verbal, designaron, respectivamente, a la persona que adquiere la cosa y a la que la cede, sin que en ningún momento se produjeran neutralizaciones ${ }^{15}$. Los dos significados aparecen muy bien delimitados en el siguiente ejemplo del Fuero de Soria, por ejemplo:

Mas si el uendedor non diere al comprador la cosa al dia o al tiempo que deuiere o si se perdiere por su culpa osi fizo pleyto que si se perdiesse o si se dannasse que fuesse el danno suyo, en estas tres guisas o en qual quier dellas deue seer el danno del uendedor. (1196)

Las dos palabras adquieren una gran importancia al ser empleadas como términos del Derecho, pues permitían distinguir claramente a los actores del negocio jurídico correspondiente.

Art. 118. En caso de venta de finca hipotecada, si el vendedor y comprador hubieron pactado que el segundo se subrogará no sólo en las responsabilidades derivadas de la hipoteca, sino también en la obligación personal con ella garantizada, quedará el primero desligado de dicha obligación [...].

2.1.2. Otros derivados sustantivos, debido a la oposición de las dos formas léxicas verbales, pasarán a significar 'el hecho de comprar' o 'el hecho de

\footnotetext{
${ }^{15}$ Incidentalmente, este valor agentivo de -dor lo mantenía su variante femenina -dera, de modo que compradera y vendedera, alternaron, al menos hasta finales del s. XVII, con la formas comprador y vendedor. El siguiente ejemplo es de 1301: «...por ruego de los dichos Lucas Pérez, vendedor, e doña María Blásquez, compradera, fiz escrivir esta carta e fiz en ella este mi signo en testimonio, e só testigo». Del mismo modo, particularmente durante el s. xv, aunque existen también ejemplos aislados ya en el s. XIV, se introdujeron, como consecuencia de una preferencia cada vez mayor por el participio de presente que había fomentado la imitación de los modelos latinos, las formas sustantivas comprante y vendiente, que no llegaron a superar, sin embargo, los límites del s. XVI, momento en que empezó a decaer esta moda estilística: «...entiendo los conprantes \& vendientes ssi quiera mareantes que por ganançias de flete \& pasadas por las mares fazen preçios...» (1417). Su interpretación como sinónimos de los sustantivos comprador y vendedor hacía que pudieran alternar con estos de modo bastante natural. Véase este ejemplo de 1448: «La quarta fija es baratería, \& ésta cometen malos mercadores \& menestrales, segunt su arte, engañando los conpradores \& vendientes por espeçiales maneras, cada vno en su arte».
} 
vender', según el verbo del que procedan. Es el caso de las formas actuales compra y venta (también venda ${ }^{16}$ ), que se remontan también a los inicios del castellano. Aunque el uso de uno de ellos sería suficiente, en algunos contextos es posible encontrar ambos:

...e non se acordaren en la compra o en la venta (1284)

Estos sustantivos deverbales se comportan también como predicados $\mathrm{y}$, como en la actualidad, podían seleccionar en el discurso el mismo sujeto y los mismos complementos (independientemente de que se hallen actualizados por el verbo de apoyo correspondiente):

Por vtilidat de mi Corte de algun acrescentamiento de mis rentas reales del mi reyno de Sicilia, quiça conuendria que se contracte y faga alguna venta de panes a essa comunidad [...] (1498)

La relación de oposición quedó tan tajantemente establecida que, desde el punto de vista del lenguaje jurídico, se ha llegado a crear un término (compraventa) para designar un tipo de contrato preciso que trata de evitar el carácter restrictivo derivado del uso independiente de uno de los dos sustantivos:

...en un contrato de hipoteca, compraventa, etc. etc. no hay fin, esto es, no hay causa del negocio jurídico, porque cada parte tiene intereses opuestos y contradictorios y otro tanto puede afirmarse del tratado como fuente de obligaciones. (1962).

Otros sustantivos, sinónimos de los anteriores, presentan una vida más efímera. Es el caso de compramiento, por ejemplo, que parece una formación esporádica $^{17}$ :

Si mays de tercero dia la touiere, del compramiento nadi non se puede repentir. (1300).

$\mathrm{Su}$ opuesto morfológico vendimiento, a pesar de desaparecer hacia finales de la Edad Media, tuvo mayor éxito, pues aparece en los textos con mayor frecuencia. A ello contribuyó, probablemente, el hecho de que se empleara en los documentos oficiales para designar la operación que, como hemos visto, pasó a llamarse compraventa:

16 Corominas se pregunta si tal vez la forma venta no sería un galicismo. Vid. Joan Corominas, con la colaboración de José Antonio Pascual, Diccionario crítico etimológico castellano e hispánico, Madrid, Gredos, 1980-1991.

17 Se trata, de hecho, de una palabra muy poco utilizada, pues en el CORDE encontramos solo un ejemplo, concretamente en el Fuero de Plasencia. Convendría preguntarse, tal vez, aunque sobrepasa el objetivo de este trabajo, en qué medida el origen geográfico del texto puede haber influido en este uso particular. 
...yo Pedro Dominico con mi mulier dona Teresa, et yo Martin Giraldo con mi mulier dona Marina, todos de mancomun fazemus karta de vendimiento y de roboramiento a vos Dominico Martin... (1247)

Nos encontramos, por tanto, como en el caso de los sustantivos compra y venta, con una oposición semántica, amparada también en una morfológica.

Distinto es el caso del sustantivo vendición, introducido en castellano, desde el s. XIII, a partir de la forma latina VENDITIO. Se utilizó como sinónimo de venta y vendimiento hasta bien entrado el Siglo XVI, y como este último, se empleó también para designar las cartas oficiales que hacían referencia al contrato en general (carta de vendición). Pero, al contrario de lo que sucedió con vendimiento, no provocó la creación de una forma analógica en -ción derivada de comprar (*compración). En ese sentido, alternaba en los textos con cualquiera de las otras formas léxicas, como se desprende de esta definición del Vocabulario eclesiástico de Santaella:

Si tanti agrum vendidistis. Actuum .v. Nota que todo verbo que denota vendición o compra o estimacion requiere genitiuo o ablatiuo por natura de respecto. vt ego vendo. emo. vel extimo hanc rem tribus solidis vel trium solidorum. (1499).

El sustantivo compradura, atestiguado también en la Edad Media, aunque de escaso uso -aparecen tan solo dos ejemplos en el corpus, en textos de procedencia aragonesa- no parece tener un converso morfológico. Contamos únicamente con un ejemplo accidental de un posible ventura que responde a las necesidades de la rima en los siguiente versos del Poema de José ${ }^{18}$ :

Rrogó al comprador liye volviese por mesura,

I doblar-le ia el preçio de la su compradura,

Y él no lo quiso hazer por que ya tenia ventura. (1370).

La forma véndida, tomada del latín VENDITA ${ }^{19}$, tuvo especial éxito durante toda la Edad Media; pero desapareció sin dejar apenas rastro a comienzos del s. XVI. Se opuso, fundamentalmente, al sustantivo compra, pues la variante analógica cómpreda aparece muy tardíamente en el corpus y no tuvo excesivo éxito ${ }^{20 .}$

E cuenta maestre Godofré e otras estorias que d'estas véndidas e compras fueron fechos privilegios e leis e decreto en Egipto que siempre fuesse assí. (1275).

18 Por el momento, este ventura debería formar parte del apartado que en José Antonio Pascual y Rafael García Pérez, 2006, op. cit., se ha denominado «formas de interés filológico».

19 Vid. Joan Corominas, op. cit.

20 En el CORDE aparece a partir del s. XVIII y desaparece a finales de la misma centuria. Autoridades no la recoge, aunque sí la primera edición del Diccionario usual de 1780 con la marca anticuado; se especificaba, además, que se conservaba algún uso en La Mancha. 
La actualización en el discurso de algunos de estos sustantivos predicativos que designaban 'el acto de comprar' o 'el acto de vender' refuerza su importancia. De todos los derivados del verbo comprar, solo compra selecciona, desde los primeros testimonios del castellano, un verbo de apoyo que le otorgue los rasgos de tiempo, modo y aspecto:

Todo omme puede fazer compra o vender colmenas o majada, syn ellas o con ellas, a qual cabo de Seuilla quisiere. (1367).

El caso de los derivados de vender es un poco más complejo, pues tres de ellos se ven actualizados en el discurso con el verbo hacer, aunque con diferentes grados de frecuencia. El más utilizado es, sin duda, venta; a este le sigue véndida $\mathrm{y}$, en último término, vendición.

2.1.3. Los derivados con el prefijo re- son bastante antiguos. En el s. XIII encontramos las formas revender, revendedor ${ }^{21}$ y revendimiento con el significado genérico, muy similar al actual, de 'volver a vender lo que se ha comprado'.

Que deve saber la tu merçed que quanta carestía, e mal, e daño viene a la tierra es por los que conpran para revender, quel labrador forçado ha de vender. (1237).

Un poco más tardío es el sustantivo reventa (s. XV) que desplazó a revendimiento y se ha mantenido en el uso lingüístico, como forma no marcada, hasta nuestros días.

Preguntado por que lo creia, respondio e dixo que lo creia porque este dicho testigo dixo que porque auia oydo desir muchas veses que la dicha villa de Viluao auia e tenia prebilejo sobre la carga e descarga de mercaderias e sobre las ventas e reventas... (1497).

Del problemático derivado revendista tenemos solo un ejemplo en el corpus; parece una creación esporádica para designar un tipo particular de delincuente:

Es un engaño manifiesto que anda hoy en el mundo. Que vendrá un logrero, un diablo desuellacaras, robador de la de su próximo, un tramponazo, usurero, revendista y trampista, y dize que no perderíe la misa cada día por cuanto hay en el mundo... (1530-1539).

21 Como en el caso de vendedor, la forma revendedera se utilizó como femenino, en muchos casos para dar incluso nombre a la profesión (siglos XVI y XVII). 
Como opuestos, llegan hasta el s. XVII el verbo recomprar y el sustantivo recompra, menos difundidos que revender o reventa.

y renuncia la recompra de las villas y castellanías de Lilleduay y Orches. (1604-1618).

2.1.4. Un caso muy particular ${ }^{22}$ es la forma retrovender, que se estableció principalmente en el lenguaje jurídico desde el s. XVI, aunque su más amplia difusión se produjo a finales del s. XIX:

...el dicho señor Rey de Portugal no será mas obligado á recibir el dicho precio ni á retrovender el derecho y accion que el dicho señor Emperador é Rey de Castilla por cualquier via y manera que sea podria tener á ello antes que aquel por virtud de este contrato tenga vendido y renunciado y traspasado en el dicho señor Rey de Portugal... (1519-1547).

El significado fue heredado también por el sustantivo retroventa (s. XIX). Este se impuso como término genérico, además, para la denominación de un pacto jurídico específico (pacto de retroventa) que durante los siglos anteriores se había conocido como pacto de retrovendendo.

Aunque los opuestos retrocomprar y retrocompra son posibles, parecen haber tenido menos éxito que los equivalentes morfológicos derivados de $v e n d e r^{23}$.

\subsection{El modelo de «alquilar»}

Si un diccionario histórico ha de trabajar con acepciones, parece razonable partir del principio de que las relaciones de oposición no se reflejan únicamente en formas léxicas distintas, como hemos visto en el modelo anterior. Los opuestos por conversión han de acoger casos como alquilar ${ }_{1}$ ('ceder el uso de una cosa a cambio de dinero') y alquilar ${ }_{2}$, ('adquirir el uso de una cosa a cambio de dinero'), relación de enorme importancia histórica también, pues se originó muy temprano — $\mathrm{s}$. XIII- y se ha conservado hasta nuestros días.

Toma la significacion del que alquila que es el sennor de la heredat... (12541260)

Tod aquel de cabo que cassa alquilare et la desenparare, no sabiendolo el senor dela cassa, torne el loguer doblado al sennor. (1218-1250)

${ }^{22}$ Retro- lo consideran prefijo algunos autores. Vid., por ejemplo, Soledad Varela y Josefa Martín García, «La prefijación», Gramática descriptiva de la lengua española, Ignacio Bosque y Violeta Demonte, dirs., Madrid, Espasa Calpe, 1999, págs. 4993-5040.

${ }^{23}$ No he encontrado ejemplos ni en el CORDE ni en el CREA, aunque sí en textos tomados de internet. 
Ambas acepciones conversas se relacionan con otras sinónimas, como arrendar y alogar ${ }^{24}$, existentes, al menos, desde el mismo s. XIII; de ellas, la segunda, por ser básicamente aragonesa ${ }^{25}$, quizás haya encontrado más dificultades para permanecer en la corriente de la historia del castellano; así, solo alquilar y arrendar han llegado hasta nuestros días.

2.2.1. En lo que respecta a los derivados en -dor, heredaron la misma oposición semántica interna que los verbos de los que proceden, de modo que, desde muy temprano, nos encontramos, en la lengua general, con unas relaciones simétricas entre todos ellos que podrían representarse por medio del siguiente cuadro:

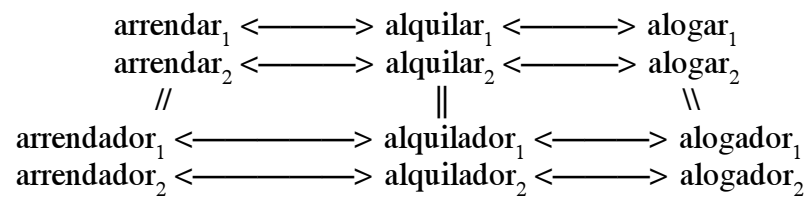

Este equilibrio se vio perturbado un poco más tarde, cuando la aparición de la forma arrendatario - término que aportaba una mayor claridad designativa- en el campo del Derecho (siglos XIV y XV), hizo que arrendador terminara perdiendo su ambigüedad, y contribuyó a establecer como términos jurídicos, preferentemente, arrendar, arrendador y arrendatario. De ese modo, alquilar, y alquilador, pero sobre todo este último, quedaron relegados a la lengua general $^{26}$. Esta irrupción de la forma arrendatario resulta especialmente significativa, tanto desde el punto de vista de su construcción, como desde el de su influencia en la creación de un nuevo paradigma de oposiciones morfológicas. Está formada por un sufijo de carácter culto (-ario), adaptación del antiguo -arius, que se había utilizado en el derecho romano para denominar, precisamente, a la parte pasiva de ciertos negocios jurídicos. Así, en el caso del llamado legatum, junto al legator (o persona que dejaba a otro una parte de los bienes de la herencia) existía el legatarius (o persona que los recibía); en el del mandatum, encontramos un mandator y un mandatarius, y lo mismo puede predicarse del commodatum (commodator / commodatarius), o del depositum

${ }^{24}$ Dejaré de lado en este momento alquilear.

25 José Antonio Pascual, «Los aragonesismos en La visión deleitable del Bachiller Alfonso de la Torre», Actas del I Congreso Internacional de Historia de la Lengua Española, Madrid, Arco/ Libros, 1988, págs. 647-676.

${ }^{26}$ Aunque los dos primeros puedan aparecer en textos especializados, no se utilizan para designar conceptos o leyes, contrariamente a lo que sucede con arrendar y sus derivados: Ley de arrendamientos urbanos, arrendamiento de servicios, etc. 
(depositor / depositarius). El sufijo se aplicaba al supino de la forma verbal correspondiente ${ }^{27}$, que reforzaba, evidentemente, su sentido pasivo. Los primeros vocablos introducidos en romance son préstamos del latín, integrados, también, en el campo del derecho. En el s. XIII nos encontramos ya con la forma legatario, al menos en el ámbito dialectal ${ }^{28}$.

Et en quoál guisa deua ser demostrado el testament al legatario, de suso es dito expressament en el título «De edendo». (1250).

A imitación de estos cultismos se crearon nuevas palabras a partir de las raíces latinas, como donatario (s. XIV), del supino DONATUM. El neologismo arrendatario supuso un paso más en la difusión del sufijo -ario con sentido de opuesto converso, pues partió de una forma puramente castellana (arrendar) que, por analogía con el latín, cuenta con una especie de supino latente (*ARRENDATUM). Con el tiempo, se irá ampliando la nómina de términos, y no siempre en el ámbito jurídico (prestatario, consignatario, destinatario, etc.) ${ }^{29}$.

El paso de arrendatario a la lengua general hizo que hoy en día, tras la culminación de todos los procesos de reestructuración entre sinónimos y derivados, nos encontremos con una situación que podría representarse del siguiente modo:

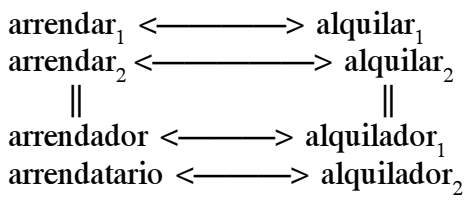

En el lenguaje jurídico, sin embargo, asistiríamos a la pérdida del converso alquilador:

27 Esto implica que no todos los derivados presenten una -t- en la raíz, como sucedió con commissarius, derivado de committo, ya existente en el latín vulgar. Se ha de partir, por tanto, de un único sufijo -ario, del que -tario no sería más que una variante por analogía con las formas más frecuentes del antiguo supino. Algunos autores, al hacer un análisis sincrónico, plantean la posibilidad de que, en casos como este (arrendatario, asignatario, destinatario) podamos hablar de «un alomorfo -tario, creado por estereotipia y activo en el ámbito de la terminología jurídica»: José Carlos Martín Camacho, El problema lingüístico de los interfijos españoles, Cáceres, Universidad de Extremadura, 2002.

28 Vidal Mayor. El CORDE no nos muestra ejemplos para el s. XIV; solo aparecen de nuevo, ya instalados definitivamente en el castellano, a partir del s. XV.

${ }^{29}$ El sufijo, además, se ha reinterpretado y ha pasado a tener un sentido activo, en ejemplos del tipo protestatario, fedatario, signatario, etc. Esta cuestión es, sin duda, de gran interés para un diccionario histórico. 


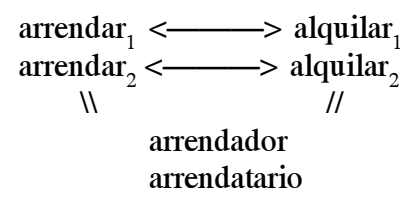

2.2.2. Los sustantivos deverbales, en principio, heredaron también la ambigüedad de los vocablos de partida. El primero, arrendamiento (s. XIII), se utilizó para designar tanto la acción de ceder una cosa a cambio de una contraprestación económica como la acción de recibirla y, con este doble significado, se mantuvo en la lengua general y, especialmente, en la del derecho, aunque ya no solo como un elemento más de la terminología - junto a arrendar, arrendador y arrendatario-, sino como denominación general del negocio jurídico. No obstante, no era infrecuente que se hiciera de modo expreso una distinción entre las dos acepciones gracias a su actualización en el discurso por medio de ciertos verbos de apoyo. Mientras las combinaciones con el verbo hacer no solucionaban el problema de la doble interpretación del sustantivo, el recurso al verbo tomar suponía una voluntad clara de especificar su sentido converso:

Pero si aquel que era en tenencia dela uilla crouiesse en buena fe que nol sacaron el derecho del padronadgo quando tomo el arrendamiento. (1256-1263).

Con el tiempo, el sustantivo arrendamiento pasó a formar parte de un sintagma preposicional directamente dependiente del verbo pleno tomar, que regía como objeto directo el objeto arrendado. Hasta el s. XVI se usaba la preposición por (tomar por arrendamiento) $\mathrm{y}$, desde esa fecha en adelante, se ha venido prefiriendo la preposición en (tomar en arrendamiento). Precisamente, esta distinción de acepciones en el discurso propició que, un poco más tarde, se hiciera necesario especificar también, de modo expreso, la acción que ejecutaba el arrendador. En ese sentido se introdujo el opuesto del verbo tomar (s. XV) en expresiones sintácticamente equivalentes, como dar a arrendamiento y, sobre todo, a partir de los siglos de Oro, dar en arrendamiento:

...e dixo que arrendaba e dio en arrendamiento a doña Leonor de Cortinas, viuda, vecina desta dicha villa, unas casas suyas propias que ha e tiene en esta dicha villa... (1593).

El término arrendamiento, por otro lado, adquirió, al menos contextualmente, el sentido concreto de 'precio o cantidad que debía satisfacerse según el contrato'. No era infrecuente, por tanto, que se viera seleccionado como complemento directo por dos pares canónicos de opuestos: pagar y cobrar:

...e qualquier de vos finado que el otro que fincare que pague el arrendamiento sobredicho e lo tenga en su poder por toda su vida... (1269). 
La variante alquilamiento es mucho más tardía (s. XVI). Presentaba también los dos significados, pero apenas tuvo difusión y terminó desapareciendo antes del s. XVII. Más éxito tendría el derivado de alogar, en su forma alogamiento o logamiento, que se remonta al s. XIII, al menos en el ámbito dialectal, y se mantuvo en el uso lingüístico tanto tiempo como el verbo del que procedía. Tenía el mismo carácter ambiguo que el resto de los elementos estudiados de la familia, y lo mantenía incluso en el momento de su actualización por medio del verbo de apoyo hacer:

Pagar deuen los arrendadores \& los alogadores el preçio de las cosas que arrendaren o alogaren segund la costunbre que fuere vsada en cada vn lugar o al tienpo en que se avinieren quando se fiziere el arrendamiento o el alogamiento. (1491).

La forma arrendación es, probablemente, de procedencia dialectal. Los primeros ejemplos del corpus son aragoneses (s. XV). Se trataba de un derivado que se mantuvo en el uso lingüístico apenas un siglo y podía interpretarse como la acción de arrendar (en sus dos sentidos conversos) y como el precio que habría de pagarse. Este sustantivo no tuvo un equivalente en las familias de alquilar y alogar (*alquilación o *alogación).

A partir del s. XV nos encontramos también con la el sustantivo arriendo, resultado de un proceso de derivación regresiva. Como sucedió con arrendamiento, heredó los dos significados opuestos del verbo arrendar, y se ha mantenido en el uso lingüístico hasta nuestros días, aunque no ha sido objeto de tratamiento particular en la lengua especializada. Ha tenido gran éxito, sin embargo, en la lengua general, donde se ha comportado como un sinónimo de arrendamiento a todos los efectos: como este, ha seleccionado hacer como verbo de apoyo, y ha admitido otras combinaciones con los verbos dar y tomar para especificar en contexto los dos sentidos conversos:

...se han visto precisados los vecinos á entrar en los términos de Sollana, de Carlét, del Marquesado, comprando ó tomando en arriendo varias haciendas. (1795).

Del mismo modo, adquirió el sentido de 'precio' y funcionó como objeto directo de los verbos pagar o cobrar:

Pocos le quedan á un arrendatario despues de pagar los derechos á la Iglesia, al Estado y á los Señores territoriales, y despues de satisfacer los arriendos, que se aumentan continuamente... (1795).

Los verbos alquilar y alogar presentaron algunos derivados especiales. El 
sustantivo alquiler (y sus variantes alquilé $e^{30}$ y alquiley) se comportaron de modo regular y heredaron los dos significados opuestos de la forma verbal. Ha sido, sin duda, uno de los de mayor éxito en castellano. También en este caso, fue posible especificar contextualmente los dos sentidos conversos desde muy temprano:

Qui casa diere ad alquile o la tomare, aquel qui la tomare, si la dexare fata cabo de anno, del todo el alquile. (1242-1275).

Del verbo alogar proceden aloguero o loguero y aloguer o loguer, en todos los casos con los dos sentidos conversos tradicionales, que, como los anteriores, podían diferenciarse contextualmente al integrar ciertas estructuras sintácticas con los verbos dar y tomar:

Et de mas tenemos por bien, e con tal condition uos damos todo lo que sobrescripto es, que uos non lo podades tributar nin dar a loguero a ninguna perssona que sea cuentra nuestra uolundat. (1318).

Tienen arrendados los onbres vnos de otros heredades o viñas o huertas o otras cosas semeiantes: \& toman otrosi a loguero casas o tierras o otros hedefiçios. (1491).

Tanto alquiler como aloguero y sus variantes tenían también el significado de 'precio' o 'cantidad' y, por lo tanto, eran seleccionados por los verbos pagar y cobrar:

Otrossi hel que la logare del non gela pueda dexar por aquel tiempo que la logare, saluo si pagare el loguero del tiempo que la logare o fuere por conplir fastal tiempo conplido... (1196).

De alquilar provenía también el sustantivo alquiladizo (siglos XV-XVII), que no tuvo ningún sinónimo equivalente en los derivados de los verbos arrendar y alogar. En este caso, se trataba de un uso específico; se hallaba vinculado, exclusivamente, aunque de modo indirecto, con la acepción verbal de sentido activo, pues adquirió el significado de 'persona que trabajaba para otra a cambio de cierto estipendio'. Lo mismo puede predicarse de la variante sustantivada del adjetivo alquilado.

${ }^{30}$ Para la relación entre alquilé y alquiler, vid. Joan Corominas, op. cit. También los volúmenes del Diccionario Histórico publicados interpretan estas dos formas como variantes de una misma palabra. Vid. Real Academia Española, Diccionario histórico de la lengua española, Madrid, imprenta propia, 1960. 


\subsection{El modelo de «legar»}

El verbo legar, término jurídico culto, apareció tardíamente en castellano (s. XV-XVI) con el significado de 'dejar una cosa testamentariamente a título particular'. Si en este momento nos interesa es porque, contrariamente a lo que hemos visto en los modelos anteriores, nos encontramos con un verbo que no tiene un opuesto converso, ni como forma léxica independiente, ni como acepción particular dentro de la misma palabra, pues legar se interpretó siempre, siguiendo el modelo latino, en un sentido unidireccional:

No solamente puede el testador legar cosa suya propria o en que hoviesse derecho, mas aun la de su heredero, y aun de otro estraño, si él sabía quando la legó que era agena. (1540-1553).

El converso de legar se expresó, más bien, con una estructura sintáctica en la que intervenía el sustantivo legado (siglos XV y XVI) y el verbo de apoyo recibir, sobre todo a partir del s. XIX. Se establecía así una oposición indirecta que se añadía a una oposición directa con la estructura más antigua «hacer o dejar un legado»:

Si el demandado recibió un legado de 5.333 pesetas y no se ha probado que consumió dicha cantidad, no puede decirse que sólo cuente con el salario que su oficio le proporciona. (1889).

Estas relaciones de oposición imperfecta se han mantenido hasta nuestros días. Podrían representarse por medio del siguiente cuadro:

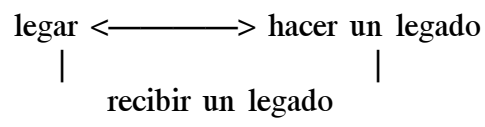

Aunque la combinación con hacer sigue siendo la más frecuente hoy, el lenguaje jurídico ha admitido también nuevas variantes, como establecer, disponer e incluso ordenar, en un sentido más especializado: 'el acto de determinar el conjunto de bienes que serán entregados a título particular’:

Es fácil establecer un legado para IPPF/RHO; sencillamente nómbrenos en su testamento ${ }^{31}$.

Naturalmente, legado también se interpretó, desde muy temprano, como 'cosa legada', lo que llevó a que fuera seleccionado, a su vez, por predicados del tipo entregar o adquirir, pero, al mismo tiempo, no era raro que se combi-

31 Tomado de internet: http://www.ippfwhr.org/donate/donate_planned_s.html. 
nara con otros que no siempre ayudan a deshacer su ambigüedad en ciertas oraciones, como haber, desaparecido en los Siglos de Oro, cobrar o el mismo recibir:

El que recibe una herencia ó legado y los vende después, no puede impugnar como nulo el testamento correspondiente. (1889).

A veces, en ciertos contextos, es frecuente que se lleguen a utilizar los verbos de apoyo más recientes como sinónimos de un verbo pleno, debido quizás a la fuerza que han cobrado estas solidaridades léxicas en el campo del lenguaje especializado y a la tendencia de la lengua general por escapar de los llamados comodines ${ }^{32}$ :

Las monjas de La Enseñanza, que administraban el legado establecido por doña Clemencia Caicedo a fines de la Colonia, continuaron a cargo de la educación femenina en la ciudad al frente del colegio de La Enseñanza, al que acudían sobre todo niñas de padres acaudalados de Bogotá. (1992).

El derivado más antiguo que aparece en los textos es legatario (s. XIII), préstamo directo del latín, formado sobre el supino legatum, como he señalado más arriba. Designaba a la persona que recibía los bienes según la disposición testamentaria. El hecho de que apareciera antes que la forma verbal no tiene nada de extraño, pues esta familia léxica estaba muy ligada a la idea de herencia y testamento, de modo que, si desde muy temprano, por razones de ambigüedad, se sintió la necesidad de distinguir entre el heredero (o sucesor natural de una herencia) y el legatario (o persona que recibía ciertos bienes por una disposición particular), en el caso de los verbos la necesidad no era tan perentoria, pues se venían utilizando, como hemos visto, otros verbos semánticamente genéricos que se combinaban también con el sustantivo herencia:

...e si tenié tanto como avié dado por ello, sacadas las cuestas e las missiones que avié ý fechas, dexava su herencia al señor cuya fuera... (1275).

La existencia del término legatario no favoreció una forma opuesta en -dor, como había sucedido con otras familias léxicas ${ }^{33}$. La razón era que, en la práctica, el supuesto «legador» coincidía con la persona que hacía el testamento, de modo que lo más natural fue que, desde un principio, se estableciera una única

${ }^{32}$ José Antonio Pascual, «¿Pobreza o confusión de registros? A propósito de la precisión en las elecciones del eje sintagmático», Pulchre, bene, recte. Estudios en homenaje al profesor Fernando González Ollé, Saralegui Platero y Manuel Casado Velarde, eds., Pamplona, Eunsa, 2002, págs. 1025-1051.

${ }^{33} \mathrm{El}$ latín sí contaba con un legator opuesto a legatarius, aunque no parecía usarse con tanta frecuencia. 
relación de oposición imperfecta entre testador y legatario, en paralelo a la existente entre testador y heredero.

Siendo mandadas a alguno todas las cartas suyas, no se entendería de los libros que hoviesse el testador, salvo si el testador y legatario fuessen letrados o aprendiessen para ser letrados. (1540-1553).

\section{CONCLUSIÓN}

He tenido la ocasión de presentar tres modelos de agrupación de las acepciones partiendo de las relaciones de oposición establecidas por la Semántica. Estas conexiones tienen enorme interés para la confección de un diccionario histórico, pues nos muestran que las palabras no están aisladas, sino que forman una compleja estructura que hemos de tener en cuenta si queremos entender, en toda su complejidad, la evolución del léxico de una lengua.

\section{APÉNDICE}

MODELO N. ${ }^{\circ} 1$

\begin{tabular}{|l|l|}
\hline Comprar (s. XII-s. XXI) & Vender (s. XII-s. XXI) \\
\hline Comprador (s. XII-s. XXI) & Vendedor (s. XII-s. XXI) \\
Compra (s. XII-s. XXI) & Venta (s. XII-s. XXI) \\
Compramiento (s. XIV) & Vendimiento (s. XIII- s. XVI) \\
& Vendición (s. XII- s. XVI) \\
Compradura (s. XIV) & Ventura? (s. XIV) \\
Cómpreda? (s. XVIII) & Véndida (s. XIII-s. XVI) \\
Recomprar (s. XV- s. XVII) & Revender (s. XII- s. XXI) \\
& Revendimiento (s. XIII) \\
Recompra (s. XV- s. XVII) & Reventa (s. XV- s. XXI) \\
& Revendedor (s. XIII- s. XXI) \\
Retrocomprar? (s. XX- s. XXI) & Revendista? (s. XVI) \\
Retrocompra? (s. XX- s. XXI) & Retrovender (s. XVI- s. XXI) \\
& Retroventa (s. XVI- s. XXI) \\
\hline
\end{tabular}


MODELO N. ${ }^{\circ} 2$

\begin{tabular}{|l|l|}
\hline Alquilar $_{1}$ (ss. XIII-XXI) & Alquilar $_{2}$ (ss. XIII-XXI) \\
\hline Alquilador (ss. XIII-XXI) & Alquilador (ss. XIII-XXI) \\
Alquilamiento (ss. XVI- XVII) & Alquilamiento (ss. XVI-XVII) \\
Alquilé & Alquilé \\
Alquiley & Alquiley \\
Alquiler (ss. XIII-XXI) & Alquiler (ss. XIII-XXI) \\
Alquiladizo (ss. XV-XVII) & \\
Alquilado (ss. XV-XX) & \\
\hline
\end{tabular}

\begin{tabular}{|l|l|}
\hline Alogar $_{1}$ (ss. XIII-XVI) & Alogar $_{2}$ (ss. XIII-XVI) \\
\hline Alogador (ss. XIII-XIV) & Alogador (ss. XIII-XIV) \\
Alogamiento (ss. XIII-XVI) & Alogamiento (ss. XIII-XVI) \\
Loguero & Loguero \\
Loguer & Loguer \\
Aloguer & Aloguer \\
Aloguero (ss. XII-XVI & Aloguero (ss. XII-XVI) \\
\hline
\end{tabular}

\begin{tabular}{|l|l|}
\hline Arrendar $_{1}$ (ss. XIII-XXI) & Arrendar $_{2}$ (ss. XIII-XXI) \\
\hline Arrendador (ss. XIII-XXI) & Arrendador (ss. XIII-XXI) \\
& Arrendatario (ss. XIV-XXI) \\
Arrendamiento (ss. XIII-XXI) & Arrendamiento (ss. XIII-XXI) \\
Arrendación (ss. XV-XVI) & Arrendación (ss. XV-XVI) \\
Arriendo (ss. XV-XXI) & Arriendo (ss. XV-XXI) \\
\hline
\end{tabular}

MODELO N. ${ }^{\circ} 3$

\begin{tabular}{|l|l|}
\hline Legar (ss. XV-XXI) & \\
\hline $\begin{array}{l}\text { (Hacer) legado (ss. XV-XXI) } \\
\text { Testador }\end{array}$ & (Recibir) legado (ss. XIX-XXI) \\
Legatario (ss. XII-XXI)
\end{tabular}

